\title{
AS NOÇÕES DE ACEITABILIDADE/ JUSTIFICABILIDADE NA DESCRIÇÃO DO FUNCIONAMENTO ARGUMENTATIVO DA LINGUAGEM
}

\author{
Ana Zandwais
}

RESUMO: This article describes the relation between two different theses on The Theory of Agumentation. The former explains the semantic properties of language as responsible for variation of sense within the utterances. The latter deals with variation of sense according to the principle of poliphony.

PALAVRAS-CHAVE: argumentação, topoï, língua, polifonia, movimento dos sentidos, lugares de enunciação.

\section{INTRODUÇAO}

O presente estudo propõe-se a realizar um percurso que abrange dois momentos distintos da Teoria da Argumentação proposta por Oswald Ducrot. Um primeiro momento que se configura por apresentar princípios teóricos envolvidos na Teoria da Argumentação na Língua, cujas bases estão sustentadas por condições de aceitabilidade/justificabilidade e pela

Ana Zandwais é professora do Instituto de Letras da UFRGS. 
inscrição do topos na língua. E um segundo momento, configurado como Teoria Polifônica da Argumentação, em que as condições anteriormente impostas às relações de encadeamento entre argumento e conclusão perdem seus alicerces para que sejam sustentadas por pressupostos de natureza distinta.

AS CONDIÇÕES DE EXISTENNCIA DOS TOPOI NA TEORIA DA ARGUMENTAÇAO NA LÍNGUA

Partindo da premissa de que os pressupostos que embasam as teorias argumentativas e tomam por base aspectos externos à língua, tais como leis sociológicas, psicológicas, retóricas não tratam, de forma adequada, do funcionamento das estruturas da língua em relação à especificidade do papel argumentativo que estas estruturas desempenham, Ducrot (1989) propõe-se a rever esta condição marginal atribuída ao componente lingüístico, através de uma teoria que ele designa de Teoria da Argumentação na Língua, cuja relevância para os estudos da linguagem consiste em descrever valores argumentativos distintos que determinados morfemas tomados como equivalentes, quer dentro do âmbito da lógica formal, quer em virtude da ausência de critérios semântico-lingüísticos, ${ }^{1}$ adquirem enquanto variáveis argumentativas que podem apresentar uma força ilocutória X ou Y e conduzir argumentos (r) para uma conclusão C. E conforme o próprio Ducrot (2002, p. 13) assevera a respeito da questão:

não se trata de descrever os mecanismos lógico-psicológicos da argumentação, mas somente os discursos argumentativos em particular, os encadeamentos de dois segmentos $\mathrm{A} \mathrm{e} \mathrm{C}$, em que um é apresentado como argumento justificando outro, dado como conclusão

Nesta fase de sua investigação, o autor parte do pressuposto de que os encadeamentos colocam em jogo uma "garantia" que autoriza a passagem de A a C. É essa garantia que ele designa como topos. Atribui, então, à noção de topos um papel central dentro da teoria, noção esta tomada por empréstimo da lógica aristotélica ${ }^{2}$, mas que é ressignificada, pois as bases que descrevem as condições de funcionamento dos topoï, ou

${ }^{1}$ Esta controvérsia remete diretamente à teoria que Ducrot(1989) designa de Tradicional, caracterizando-a por um tratamento "empírico" dado à descrição semântica dos morfema da língua.

${ }^{2}$ Reportamo-nos, fundamentalmente, à concepção que Aristóteles adota em Tópicos (1987) e que define os topoi como premissas que, não podendo ser julgadas nem em termo de verdade ou falsidade, passam a constituir um conjunto de premissas, cuja aceitabilidade depende de um consenso entre aqueles que são reconhecidos como detentores do saber na sociedade grega. 
estão determinadas por estrutura ou por saberes já cristalizados no interior da própria língua. Assim, Ducrot caracteriza os valores argumentativos de um morfema $x$, enquanto uma variável, como instruções semânticas que devem atender a certas condições lógicas, mas que, ao mesmo tempo, deixam de enquadrar-se no modelo das operações algorítmicas. ${ }^{3}$ A razão que o leva a recusar a hipótese formalista da existência de algoritmos de paráfrase, dentro da Teoria da Argumentação, pode ser justificada pelo fato de que para uma teoria formal sobre a língua a questão central na caracterização das equivalências entre estruturas deve levar em conta as condições de verdade a que são submetidos os enunciados, mas não as diferenças de efeitos semânticos deriváveis de operações de substituição, supressão ou acréscimo de morfemas às mesmas estruturas. Desse modo, conforme Ducrot (1989, p. 17), os esquemas binários impedem a observação do comportamento peculiar que determinadas correspondências "sinonímicas" assumem, tornando-se inviável, muitas vezes, demonstrar que estes esquemas funcionam, de modo abstrato, impedindo o movimento de passagem de estruturas binárias ou equivalentes para conclusões não-análogas.

A partir desta perspectiva, Ducrot passa a considerar que x pode ser tomado como um operador argumentativo se cumprir simultaneamente as seguintes condições: a) dentro de um enunciado(e) puder constituir uma operação argumentativa através de recursos de adição ou substituição, como ocorre em (1' ) João correu pouco, enquanto uma operação de acréscimo de (1 ) João correu; b) se a inserção de x em (1) determinar orientações argumentativas diferentes para 1 e 1', as quais devem derivar da estrutura e não de uma diferença situacional associada a cada enunciado; c) se os próprios enunciados puderem indicar como se argumenta ou não a partir deles, autorizando ou interditando certas possibilidades de encadeamentos. Dentro desta ótica, portanto, a noção de topos, conforme Ducrot (1995), é que permite sustentar a passagem do argumento à conclusão, considerando que o topos está na língua.

A fim de elucidar e de problematizar, ao mesmo tempo, a questão retomamos alguns morfemas apresentados por Ducrot (1989, p. 39).

Se tomarmos, inicialmente, dois enunciados como Pedro correu pouco ( $\left(\mathrm{P}^{\prime}\right)$ e Pedro correu um pouco $(\mathrm{P}+\mathrm{x})$ e considerarmos que $\mathrm{P}+\mathrm{x}$ constitui um operador argumentativo derivado de $\mathrm{P}$ ', por acréscimo, mas que este último não admite os mesmos conjuntos de encadeamentos que $\mathrm{P}$ ' admite, podemos afirmar, então, que $\mathrm{P}+\mathrm{x}$ tem força ilocucucionária di-

${ }^{3}$ Fazemos referência às relações de equivalência binária que, segundo a lógica formal, regulam as operações de parafrasagem no interior de cada língua. 
ferente de P' em virtude do acréscimo de um morfema que pode autorizar ou interditar determinadas conclusões. Assim, se de (P') 'Pedro correu pouco' pode-se concluir $\mathrm{C} 1$ ( Ele não tem chances de competir $\mathrm{C} 2$ (Ele não está preparado fisicamente ), de $\mathrm{P}+\mathrm{x}$ pode-se concluir, ao contrário, $\mathrm{C} 1^{\prime}$ (Ele vai entrar na competição), C2' (Ele está com preparo físico).

Do mesmo modo, se tomarmos dois enunciados, onde a substituição de um morfema por outro evidencia uma mudança de referência sustentada por relações de gradualidade como em (P') Esta roupa é bem excêntrica e ( $\mathrm{P}$ ") Esta roupa é demasiado excêntrica, podemos encadear $\mathrm{C} 1$ (Você vai impressionar os convidados) a P', mas, segundo Ducrot, um encadeamento como C2 (Você será um vexame) somente estaria autorizado para P", em virtude do tipo de passagens diferentes que os advérbios bem e excessivamente autorizam como operadores argumentativos que, constituindo diferentes escalas graduais, permitem descrever as condições que determinam a passagem de um movimento argumentativo para uma conclusão oposta àquela obtida pela inserção de um sintagma com valor escalar inferior, como ,por exemplo, ocorre, neste caso, com os advérbios bem e excessivamente. Por este prisma, então, ao considerar que o sintagma adverbial excessivamente, ao substituir bem, confere ao enunciado uma outra força ilocucionária que aponta para o limite da condição de excentricidade como atributo positivo, estaria autorizada a passagem de uma determinada conclusão, com valor apreciativo, para outra com efeito depreciativo.

Para conseguir postular, deste modo, a tese de que a passagem de um argumento para uma conclusão, em termos de possibilidade de encadeamento, pode sustentar-se no âmbito da língua, isto é, a partir das próprias instruções semânticas que os morfemas imprimem nos enunciados, Ducrot passa a alicerçar o trabalho da argumentatividade em propriedades específicas que ele atribui à noção de topos, tais como: a) universalidade, que representa um princípio de partilha de saberes entre uma comunidade, um grupo; b) a generalidade, que postula a necessidade de que um determinado saber seja válido para um número representativo de situações análogas, enquanto uma decorrência da condição de universalidade do topos; c) a gradualidade, que incide em variações das propriedades dos morfemas inseridos nos enunciados, de tal modo que este princípio justifica tanto uma condição de homogeneidade entre os predicados mobilizados por um topos, como sustenta, ao mesmo tempo, o fato de que não se pode passar de um lugar, uma perspectiva para outra, senão pela mediação de escalas, de relações graduais. Assim, por exemplo, ao dizermos (r1) ${ }^{4}$ Pedro pega os 
materiais dos colegas sem pedir licença, podemos avançar, em termos graduais, para outro argumento (r2)' Ele também pega o dinheiro dos outros sem pedir', a fim de orientar para uma conclusão do tipo C (Tenha cuidado com ele). Este protótipo de movimento argumentativo, portanto, nos remete à possibilidade de descrever o funcionamento de uma estrutura do tipo $\mathrm{X}$ e também $\mathrm{Y}$ por um percurso linear; isto é, por movimentos simétricos que direcionam os argumentos para uma mesma perspectiva: a de que Pedro não é confiável.

É, pois, a partir do princípio de gradualidade que se pode constatar que determinadas estruturas sintáticas como $X$ e também $Y$, não só $X$ mas também Y, Além de X, Y possam ter seus predicados apresentados como homogêneos; isto é, definidos em termos de uma mesma orientação argumentativa, a fim de justificar uma única conclusão, seja esta positiva ou não como em: (r1) ' João não só trata bem da mulher (r2) mas cuida dos filhos. C (Ele é bom marido) ou (r2) 'João falta às aulas (r2) e também não estuda. C ( Ele não tem responsabilidade).(r1) 'Além de sustentar a casa, (r2) João ajuda a mulher nas tarefas domésticas ' $\mathrm{C}$ (Ele é bom companheiro).

Por outro lado, tendo em vista que Ducrot $(1999, \text { p. } 3)^{5}$ quer manter dentro desta Teoria a hipótese de que se pode "restringir tipos de combinações discursivas a serem levadas em conta na descrição lingüística", ele passa também a conter as possibilidades "abertas" 6 de encadeamento entre argumento e conclusão com base nos critérios de aceitabilidade e justificabilidade. O primeiro, estando relacionado a princípios que, por força da repetibilidade, cristalizam-se na língua, passa a apresentar o valor semântico das palavras como uma espécie de partilha, ou de uma referência que se estabiliza, à semelhança de um senso comum, na ordem da língua, de tal modo que infringir o critério da aceitabilidade implicaria infringir este senso comum, que ao valorizar determinados princípios, passa a excluir ou interditar outros. Assim, por exemplo, ao valorizarmos o princípio da economia, podemos admitir que um enunciado como 'Um pacote turístico para a Europa sai caro' possa ser encadeado a conclusões do tipo C1 (É preciso ter bastante dinheiro) C2 ( Não dá para viajar senão pagando em prestações), mas ficam interditadas, por exemplo, conclusões do tipo C3 (Vamos adquirir imediatamente) C4 (Esta é uma boa oferta).

${ }^{5}$ Fazemos referência ao texto "Os Topöi na Teoria da Argumentação na Língua", traduzido por Atiê Figueira e que compõe parte do livro "Lieux communs, topöi, stéreotypes, clichês, publicado pela Editora Kimé (1993).

${ }^{6}$ Referimo-nos a conjuntos de possibilidades não-autorizadas somente por estrutura, mas decorrentes das condições em que a estrutura e a exterioridade se intersectam. 
Considerando, todavia, que estes encadeamentos devem ocorrer, na prática, ainda que estruturados sob outra forma lógica, Ducrot postula o princípio da justificabilidade não somente para sustentá-los mas, sobretudo, a fim de sustentar o fato de que a própria língua oferece "garantias" para regular as condições de encadeamento entre argumentos e conclusões admitidos como "não-aceitáveis". Assim, se não se pode fazer uma passagem do argumento ${ }^{\circledR}$ 'Um pacote turístico para a Europa sai caro' para a conclusão C ( Esta é uma boa oferta), trata-se de justificá-la, isto é, autorizar a passagem através da inserção de um operador argumentativo como entretanto, operador este que funciona como uma garantia de que "a argumentação tem valor" 'Um pacote turístico para a Europa sai caro (r1), entretanto vou comprá-lo ( $r 2)$.' A restrição feita, portanto, pelo sintagma adjetivo caro ao ato de comprar fica mantida pela justificação apresentada em r2. Deste modo, conforme Ducrot (1995), a escolha de um topos tornase tão essencial quanto a escolha de um operador argumentativo, já que aquilo que uma enunciação põe em discordância em relação ao topos selecionado, pode ser revertido pela seleção de um determinado operador, como ocorre, por exemplo, em ' $O$ mar, no litoral nordestino, costuma estar calmo convidativo para nadar (r1) mas não vou nadar' (r2), onde a conjunção mas introduziria uma justificativa com o fim de refutar uma realidade usual sem negar o topos e, ao mesmo tempo, possibilitar orientação para conclusões do tipo C1 ( Irei passear) C1' ( Vou dormir).

É, portanto, através do critério da justificabilidade que os efeitos de determinados atos de argumentação deixam de ser " impróprios" para tonarem-se "apropriados", já que o que não se partilha se justifica, pelo menos. Eis uma boa estratégia para não termos de tratar com a exterioridade da língua e nem com o pressuposto de que o funcionamento argumentativo pode situar-se em "encruzilhadas", onde é possível passar de um topos a outro dentro de uma mesma situação enunciativa, sem que seja necessário admitir a condição de gradualidade do topos.

A partir desta ótica, então, podemos formular as seguintes questões: a) A validação dessa Teoria pode sustentar-se quando passamos a pressupor a não-necessidade de considerar uma relação homogênea entre o topos e os argumentos, de tal modo que se possa tomar como objeto de debate o mesmo tema a partir de lugares de enunciação distintos?

Se o ato de argumentar já se constitui, enquanto discursividade, calcado em premissas de diferença, de correlação de forças, como é possível querer restringir a natureza dos argumentos que entram em jogo para que fiquem evidentes posições que não se assimilam, dentro de um topos 
considerado homogêneo? Tais questões, segundo nosso ponto de vista, começam a ser respondidas, propriamente, por Ducrot (1988) quando o autor assume, em primeiro lugar, que assim como o valor das palavras não é integralmente lingüístico e depende de uma realidade externa - um topos - a argumentação também não se funda na língua, tendo em vista o fato de que há argumentos que se produzem em torno da própria ambigüidade de valores que são dados aos signos, determinando, em última instância, os sentidos que lhes são atribuídos. Assim, nesta fase de sua Teoria, ao aproximar-se da tese de Aristóteles de que a lógica argumentativa não se sustenta por meio de argumentos analíticos ${ }^{7}$, mas está, sobremaneira, sustentada por argumentos dialéticos ${ }^{8}$, o autor passa a ter de sustentar os fatos de que nem as expressões argumentativas são dotadas de potencial ou força ilocucionária autônoma, capaz de interditar as condições de passagem de um argumento x para uma conclusão y, nem os critérios de aceitabilidade/ justificabilidade podem descrever quais as reais condições que autorizam relações de encadeamento entre determinados argumentos e conclusões. Desta perspectiva, tomando-se um enunciado já analisado como 'Esta roupa é exuberante demais', pode-se concluir do mesmo tanto C1 (Você fará sucesso) como C2 ( Você será ridículo), pois o que determina, agora, as condições de passagem de um argumento para uma conclusão é o pressuposto de que os movimentos argumentativos não se produzem dentro de referências lineares, de tal modo que o que um operador argumentativo (um adjetivo, um advérbio, uma conjunção, etc..) pode significar somente se explica a partir de princípios que são externos à língua. É, portanto, somente a partir de uma primeira condição: a de heterogeneidade conferida ao topos, que se faz possível entender que a argumentação produz efeitos na língua, ao invés de estar determinada por instruções semânticas que lhe são "intrínsecas".

Uma segunda condição que desloca a tese anterior encontra justificativas na concepção polifônica de enunciação, proposta por Ducrot $(1987,88)^{9}$. Ao definir a realização de um enunciado como um acontecimento, cuja qualificação somente pode ser entendida a partir das condi-

\footnotetext{
${ }^{7}$ Aristóteles (1982) opõe os argumentos analíticos aos dialéticos, caracterizando os primeiros por serem formulados em termos de raciocínios dedutivos que somente autorizam conclusões particulares a partir de premissas universais, e os últimos por serem formulados em termos de raciocínios indutivos, derivando, portanto, de premissas controversas sobre a ordem do real.

${ }^{8}$ Cabe observar que em sua obra 'Analíticos Posteriores', Aristóteles questiona a relação indissociável, atribuída pelos sofistas, entre razão e verdade, já que o funcionamento dos argumentos dialéticos depende de razões que não se formulam como verdades universais. ${ }^{9}$ Reportamo-nos, fundamentalmente, aos trabalhos "Esboço de Uma Teoria Polifônica da Enunciação" (1987) e “A Polifonia em Lingüística” (1988).
} 
ções em que a enunciação se produz, Ducrot (1987) passa a contar com uma nova possibilidade: a de que o enunciado somente adquire um estatuto semântico porque remete para um lugar de enunciação e para uma perspectiva que representa este lugar. E ao assumir, sobretudo, o postulado de que um enunciado se constitui como uma superposição de vozes que se imbricam em seu interior, paga o ônus de ter de assumir também que o sentido de um enunciado se produz como um efeito das relações que entram em jogo nessa composição de vozes que o constituem. A partir daqui, a tese que atribui ao sentido a condição de efeito e à enunciação certos poderes (ibid.p.174) ${ }^{10}$ pode ser justificada, unicamente, com base no princípio de que o enunciado fala, mas através de várias vozes dispersas e de perspectivas que podem ou não se conjugar, de tal sorte que as propriedades jurídicas, causais, argumentativas dessa fala não se definem senão em relação ao modo como se produzem os enunciados; isto é, em relação ao amálgama de vozes e de posições de que são "povoados".

Desta perspectiva, ao remontarmos a encadeamentos argumentativos que, dentro da Teoria da Argumentação na Língua poderiam, no máximo, ter seus movimentos de passagem para uma conclusão descritos em termos de linearidade, agora podem ser cindidos em virtude das perspectivas a que fazem remissão, não necessitando mais, portanto, de justificações que se fundamentam em "paradigmas instrucionais" que o trabalho da descrição semântica dos morfemas da língua permite antever. É dentro dessa ótica, pois, que uma mesma estrutura pode fazer remissão a lugares distintos de enunciação, sinalizando para a evidência de que um mesmo operador argumentativo não só pode indicar movimentos argumentativos contrários, por estes configurarem lugares de enunciação topoï - que valorizam os mesmos significantes com base em princípios que são estranhos entre si, mas também com base no fato de que as condições em que se inserem cada estrutura em uma operação argumentativa possibilitam configurar formas específicas de repartição ou de sobreposições de sujeitos no enunciado. Isto é, o dito, agora, passa a ter sustentação a partir de um princípio de dispersão - a não-unicidade do sujeito - que deve responder pelas relações de consistência entre os enunciados, não mais como mero trabalho de amalgamação de uma memória homogênea, cristalizada e sacramentada na língua, mas como um efeito de condições de repartição

\footnotetext{
${ }^{10}$ Ducrot, nesta fase, retoma o conceito de Austin(1990) sobre a condição de poder da enunciação como um lugar a partir do qual são criadas obrigações para o interlocutor, de tal modo que " a virtude jurídica da enunciação consiste em fazer circular saberes sobre a própria enunciação. E o sentido, apresentado como conseqüência da enunciação, somente pode ser apreendido a partir de um lugar.
} 
de saberes em pontos de vista divididos, que se cruzam em um mesmo enunciado para atestar o modo de produção dos sentidos como uma realidade fragmentada e não-linear. Assim, estruturas como $X$ e até mesmo $Y$ ou Além de $X$, $Y$ podem comportar, ao mesmo tempo, não somente diferentes vozes, mas também perspectivas que não se assimilam entre si, configurando uma relação assimétrica entre os movimentos argumentativos que, agora, não podem mais, por razões múltiplas, oferecer "garantias" sobre o papel da aceitabilidade como condição alicerçada em hipóteses "intrínsecas". E conforme observa Ducrot $(1988$, p. 96) sobre a questão: Todo enunciado constrói uma situação... carrega uma imagem do meio em que se produz, diz algo da ideologia em que se situa.

A fim de ilustrar os comentários acima selecionamos para análise dois enunciados que tomam por objetos situações envolvendo o tráfico de drogas e clichês que identificam o perfil do brasileiro.

Considerando a situação 1(S1), que envolve um relato típico sobre o comportamento de traficantes de drogas domiciliados entre os favelados, no Rio de Janeiro, temos o seguinte enunciado: E1. ' $O$ traficante conhecido por Uê, levado para o presídio de Bangu,(r1) não só ajudava todos os favelados do morro,(r2) mas também iniciava seus filhos na prática de venda de drogas para os clientes abastados da zona sul (r3).

Como vemos, neste enunciado o locutor (12) - repórter -retoma um dito de (11) que apresenta o traficante como um indivíduo fraterno com os favelados (r2), "não só ajudava todos os favelados do morro" posto desde o lugar daqueles que foram beneficiados com o auxílio de Uê para sobreviver e outro dito (13)," mas também iniciava seus filhos na prática de venda de drogas", posto de outro lugar, que pode ser da polícia, do juizado de menores, que o apresenta como criminoso, como explorador das próprias famílias beneficiadas. Assim, ao dividir não só $\mathrm{X}$ mas $\mathrm{Y}$ em movimentos argumentativos (r2) e (r3) opostos, (12) o faz em virtude de remeter os argumentos para lugares de enunciação diferentes. Essa relação de desigualdade entre $\mathrm{r} 2$ e r3, em virtude das perspectivas a partir das quais fala, possibilita ao enunciador, em conseqüência, orientar as conclusões para perspectivas também diferentes. Assim, do lugar de (11)- os favelados poderia ser gerada uma conclusão como: $\mathrm{C} 1$ (É o crime que defende o morro), ao passo que do lugar de (13) - o juizado, a polícia - poderia ser gerada uma conclusão como: C2 (Usa o dinheiro para iniciar os filhos dos favelados no mundo do crime). E tais argumentos, embora tenham uma forma de colocação que autorizaria, sob o aspecto estrutural, acessar a 
conclusão $\mathrm{C} 2$ não podem mais servir de referência para uma única escolha, porque não se toma como parâmetro senão os lugares dos quais e para os quais se fala.

Consideremos a situação 2(S2) em que um estrangeiro, em visita ao Brasil, faz uso de um clichê para tecer comentários a respeito do brasileiro, através do seguinte enunciado: 'O brasileiro, além de ser bem humorado (r1) gosta de improvisar diante das dificuldades (r2), dando um jeito para tudo(r3)'.

Este enunciado, enquanto uma avaliação de um não-nativo (12) que fala do lugar do espectador, já traz embutido em seu interior outras vozes: a voz que configura o brasileiro como um sujeito de bom humor (11), e a voz que o define como improvisador - aquele que dá "um jeitinho" (13) - que poderia ser tanto assimilada a outras vozes no próprio país, como a vozes que avaliam o brasileiro de outros contextos histórico-geográficos. Desse modo, se considerarmos a hipótese de que (12 )assimila o ponto de vista de (13), a estrutura 'Além de X,Y' coloca em relação argumentos assimétricos que movimentam os sentidos para lugares diferentes. Enquanto r1 movimenta o sentido para um percurso de positividade, $\mathrm{r} 2$ e r3 movimentam o sentido para fazer assimilar a voz do estrangeiro (11) a outras vozes (13) que também fazem tal juízo do brasileiro, podendo remeter os argumentos para conclusões como: $\mathrm{C} 1$ (O modo como brasileiro resolve as coisas não é confiável) C2 (Não se fie em brasileiros). E desse modo, a estrutura Além de X, Y perde seu movimento de simetria que autoriza um mesmo percurso de passagem do argumento para a conclusão.

Tais relações, portanto, vêm tornar mais evidentes algumas conseqüências que podemos tirar do funcionamento das estruturas no modo de constituição de operações argumentativas, e que expomos a seguir.

Se operadores argumentativos tais como Além de $X, Y$, Não só $X$ mas $Y$ trabalham para configurar movimentos argumentativos lineares, a condição de $Y$ pode ser entendida como um movimento escalar, onde este tem força ilocucionária para garantir uma conclusão $\mathrm{C}$ que se pauta também por um percurso semântico unidericional. Mas esta condição deve ser entendida, sobretudo, como um efeito de mobilização de argumentos desde um mesmo lugar de enunciação, regulado, por isso, pelos mesmos princípios ou topoï. Por outro lado, se operadores argumentativos como Além de $X$, $Y$, Não só $X$ mas $Y$ vêm configurar argumentos assimétricos por se reportarem a lugares de enunciação distintos, temos uma divisão dos enunciados em vozes e lugares. E esta última condição torna-se fundamental porque permite caracterizar os movimentos dos sentidos, não simplesmente como decorrência de uma ordem regulada por posposições/anteposições de argumentos, onde o que é colocado em posposição adquire maior força 
ilocucionária, mas como um efeito de mobilização de argumentos a partir de lugares e para lugares de enunciação diferentes.

A partir desta última condição, portanto, o princípio da escalaridade fica sem justificativa, tornando-se desnecessário em virtude de os argumentos estarem imbricados para estabelecer uma divisão do locutor em diferentes pontos de vista. É, pois, esta condição, sob a qual o sujeito se divide em perspectivas, lugares de enunciação, que possibilita que comprovemos que a passagem de determinados argumentos para certas conclusões não depende nem de relações de escalaridade ou do estatuto que uma descrição semântica pode atribuir aos morfemas da língua.

\section{PARA CONCLUIR}

As considerações feitas nos permitem compreender que se a condição de consistência ${ }^{11}$ entre argumentos e conclusão encontra algum respaldo na ordem da língua, este alicerce somente responde às condições efetivas de funcionamento da argumentatividade a partir de relações de tensão entre o que a estrutura pode suportar e o que os lugares a partir dos quais se enuncia autorizam. Assim, para configurar o modo como os sentidos se movimentam na linguagem é preciso investigar porque um conglomerado de vozes ressonantes/discordantes se articulam nos enunciados e a partir de que perspectivas se instauram como dominantes, esvaziando, em conseqüência, a força, a legitimidade de outras. Com base em tais pressupostos, portanto, a noção de topos, abrigada na exterioridade, tanto baliza os movimentos de passagem dos argumentos a conclusões como responde pela multiplicidade desses movimentos em virtude do fato de que a própria condição do topos é dialética; assim, sendo universal ou compartilhado ele precisa ser, ao mesmo tempo, heterogêneo para abrigar diferentes perspectivas no interior dos enunciados e explicar, desde esta condição, o funcionamento discursivo das operações argumentativas, quer sejam lineares ou não.

\section{BIBLIOGRAFIA}

ARISTÓTELES. Organon: tópicos. Traduzido por Pinharanda Gomes. Vol.IV Lisboa, Guimarães Editores, 1987.

\footnotetext{
${ }^{11}$ Reportamo-nos ao conceito de Guimarães(1995) que diz respeito às relações que reenviam a interpretação de uma forma ao acontecimento enunciativo.
} 
AUSTIN, John L. Quando dizer é fazer: palavras e ação. Porto Alegre, Artes Médicas, 1990.

DUCROT, Oswald. Provar e dizer. São Paulo, Edit. Global, 1976. Esboço de uma teoria polifônica da enunciação. Campinas, Pontes, 1987.

. Polifonia y argumentación: conferencias del seminario teoria de la argumentación y análisis del discurso. Cali, Universidad del Valle,1988. . Argumentação e topoï argumentativos. In: GUIMARÃES, Eduardo (Org.). História e sentido na linguagem. Campinas, Pontes, 1989. . Topoï et formes topiques. Théorie des topoï. Anscombre, Jean Claude (Org).Paris, Kimé, 1995.

. Os topoï na teoria da Argumentação na língua. In: Revista Brasileira de Letras: lingüistica e literatura. V1. São Carlos, Universidade Federal de São Carlos, 1999.

. Topoï e formas tópicas. Ensaios: relações entre pragmática e enunciação. ZANDWAIS, Ana (org) v.17. Porto Alegre, Editora Sagra/ Luzzatto, 2002.

GUIMARÃES, Eduardo. Texto e enunciação. Organon: o texto em perspectiva. $n^{\circ} 23$. Porto Alegre, Universidade Federal do Rio Grande do Sul, 1995.

. Texto e argumentação. Campinas, Pontes, 1987

. Os limites do sentido. Campinas, Pontes, 1999.

- Semântica do acontecimento: um estudo enunciativo da designação. Campinas, Ed. Pontes, 2002.

RAJAGOPALAN, Kanavillil. A verdade na/da argumentação. In: Cadernos de estudos lingüísticos. GUIMARÃES, Eduardo(org), $\mathrm{n}^{\circ} 35$, Campinas, IEL, 1988, p.39-48. 